\title{
Organisation type and whistleblowing arrangements
}

\author{
Radu Ionescu \\ University of Bucharest, Faculty of Geography, \\ radu.ionescu@geo.unibuc.ro
}

\begin{abstract}
Hidden vulnerabilities are exposed by stressors. These stressors can be natural (flood, earthquake, heat-wave, etc.) or man-made (earthquake, flood, economic crisis, pathogen development, storage tank explosion, etc.). If the system they impact is riddled with vulnerabilities it will collapse. If a building is poorly built, because of say poor corporate ethics on the part of the contractor or corruption allowing lax observation of codes, it will collapse whether because of a natural earthquake or a man-made landslide. Whistleblowing can reveal these hidden vulnerabilities, but it also potentially manifests differently across different types of organisations, so we therefore encourage research in Romania to compare whistleblowing arrangements across the various organizational sectors.
\end{abstract}

Keywords: disaster, whistleblowing, organisations, ethics, organisational sector

\section{INTRODUCTION}

Whistleblowing can reveal the hidden vulnerabilities which facilitate disasters. This article examines some of the research that focuses on the organisational perspective concerning whistleblowing and its usefulness for both organisations and the societies they operate in.

From an organisational communication perspective, information that is perceived as destructive or negative is less likely to be transmitted to upper management. Knowledge of clear and proper channels for reporting unethical behaviour within an organization may enhance internal rather than external whistleblowing (King, 1999). Internal disclosure is preferred by organisations because it limits bad publicity and lowers the chances of regulations impacting their activities. Whether this varies depending on the organization type is something research in Romania has not dealt with.

\section{ORGANISATIONS AND WHISTLEBLOWING ARRANGEMENTS}

Companies will have a natural tendency to externalise costs. There are two major forces opposing this process: regulations and the company's desire to project an image of ethical business practices. We now focus on the latter. Business reputation is a good motivator for companies to appear to act ethically (De Castro et $a l, 2006)$. Whistleblowing can be seen as a power struggle between social actors, specifically the wrongdoer, the whistleblower, the recipient and the organisations' management. Ben-Yehuda (2001, pp. 79 in Uys, 2008) describes how the same action is interpreted in different ways by the actors involved:

"The organization sees whistle-blowing as betraying of the interests of the organization, violating the rules of hierarchy, bypassing authority, squealing, damaging the reputation of the organization, acting in a hostile manner toward the 
organization, poisoning the atmosphere, and supplanting cooperation with suspicion. Whistleblowers, on the other hand, tend to justify their activities in such terms as doing one's job, being faithful to the community, revealing the truth, and doing something that is in the best interests of the organization" (Uys, 2008: 79).

The action of whistleblowing is characterised by ethical tensions between the needs of organisations and the needs of society. But values as part of ethical systems guide action. The medical sector, especially patient care, has long-standing ethical systems in place which serve values that can be used to guide action. Other industries may not have developed values systems and whistleblowers need to find other justifications (Johnson, 2004).

One way of solving this is if the organisation indicates that it values the behaviour and provides internal channels that are an indication that the behaviour is seen as loyal (Near and Miceli, 1996). Re-conceptualising organisational loyalty as rational loyalty is another, perhaps more elegant, solution to this dilemma. Essentially rational loyalty is a loyalty that the organization and the member share for the organisations' explicit, legitimate set of mission statement, goals, value statement and code of conduct (Vandekerckhove, 2006). So, if organizational loyalty means being loyal to its values and norms (which are validated by the society it operates in because they are public), then observing wrongdoing would compel the employee to blow the whistle (Uys, 2008).

Organisations are interested in promoting silence. The whistleblower is seen as someone who violates organisational boundaries by representing "outside" moral values on "the inside". Key to this overlap is that identity is negotiated as opposed to fixed. An employee is also a citizen, a member of a family or of a community or cultural groups. This divided-self initiates hidden strategies at various levels of consciousness which means silence and whistleblowing are not the only two options (Teo and Caspersz, 2011).

Behaviour is regulated by co-workers not only by management, so it appears that the employees internalise regulations and regulate their own behaviour in terms of constant surveillance. The more he/she used dissenting discourse (jokes, gossip, codes, and sarcasm) to regulate the behaviours of others, the more it became apparent that the discourse can be used to modify his/her behaviour. This way power can be viewed as a relation (Teo and Caspersz, 2011). Every individual has the power to act ethically. The challenge is to find the effective means of exercising it.

\section{SCENARIOS}

To help researchers and managers gauge the potential harm to come from hidden vulnerabilities coming to the surface it is useful to use scenario planning (Schoemaker, 1995). Scenarios include relevant, plausible and unexpected situations and problems. Each scenario is unlikely, yet possible and uncomfortable. They help policy-makers anticipate hidden vulnerabilities and limits in organisations and methods. When identified in advance, these vulnerabilities can be better managed than during an emergency. In similar fashion, Business continuity plans with "PREsponse protocols" help deal with operational problems and deliver measurable future value-added.

Well-designed wargames allow the players flexibility and the freedom to adapt the simulated organisations. These adaptations are then stress tested by the scenario as it plays out. The game move much faster than real-life so one has the opportunity to observe years of decisions and simulated effects in the space of a day.

Military scenario planning typically follows the following steps: 1) Decide on the key question to be answered by the analysis, 2) Set the time and scope of the analysis, 3) Identify major stakeholders, 4) Map basic trends and driving forces, 5)Find key uncertainties, 6) Check for the possibility to group the linked forces, 7) Identify the extremes, 8) Define the scenarios, 9) Write out the scenarios, 10) Assess the scenarios, 11) Identify research needs, 12) Develop quantitative methods, 13) Converge towards decision scenarios.

In the past, scenario analysis in business organizations would follow current trends-lines carried into the future. These lacked demographics or qualitative differences across social aspects or conditions. Though useful these fail to consider qualitative social changes and the combined effect 
of a multitude of factors. Complex interactions are key here, as opposed to for example fault tree analysis where one may discount factors in isolation. When instead we explore the factors together we find that certain combinations can reverberate across the system and magnify to the point where this resonance can be disastrous.

For scenarios, knowledge is divided in two domains. That which we think we know. And that which we think we don't know. The first domain is mostly made up of trends which rely on past information to make prediction about the future. Some assumptions, such as those about demographics or next quarter's GDP, are quite safe to make. The second domain is populated by unknowns such as the outcomes of elections or the appearance of new technologies. When devising a scenario, the known blends with the unknown in a limited number of views of the future that encompass a multitude of possibilities. As the scenario unfolds this cone of uncertainty narrows.

These are some of limitations of scenario planning. First there is the inherent subjectivity that goes into the design. The second relates to how the game is carried out in the organisation (team composition, facilitator, etc.) and to where its focus lies (long v. short term, incremental v. paradigm shifting, etc.). There is also little that can be done to prevent political derailing, limited imagination or agenda control when running the scenario in an organisation. The third limitation is that weak integration with other planning arrangements. Dealing with multiple futures is not something all organisations are capable of. Plans and budgets follow one view of the future and are adjusted with variance analysis, renegotiations and rolling budgets. Major incidents will overcome these approaches and paralyse most organisation, their plans and budgets now rendered useless.

\section{CHALLENGES}

Simply having a procedure will have almost no impact on conduct and encouraging internal disclosures needs substantial top management support (Schmidt, 2005). Organisations that support whistleblowing and where there is value congruence between managers and whistleblowers seem to have more whistleblowers. Relatively non-bureaucratic, high performing organizations have higher rates of whistleblowing (Near and Miceli, 1996). Feldman and Lobel (2008) found that if the organization emphasizes its internal compliance systems and the voice of employees, this will have a positive effect on the willingness of a person to report unlawful behaviour within the organization and the opposite effect on external whistleblowing. However, there is somewhat of a paradox here because the organisations that support whistleblowing are generally the ones that benefit the least from it because they were open to start with (Lewis, 2006). On the other hand, the ones that oppose it are the ones that suspect the power struggle between them and society would be won by the latter should this one have the indicting information protected by the organisation.

\section{CONCLUSION}

One characteristic of the organisations that is easy to record and could enhance the picture resulting from further studies is the sector to which the organisations belong. Hersh (2002) has found no significant differences between organisations depending on their sector (specifically, the study looked at nursing compared to the army). Generally, organisations are categorised in to three sectors: the governmental, public or first sector; the business, private or second sector; and the non-governmental, non-profit or third sector (Defourny et al, 2001). We therefore encourage research in Romania to compare whistleblowing arrangements across the various sectors.

\section{REFERENCES}

Defourny, J., Borzaga, C., \& Defourny, J. (2001). From third sector to social enterprise (pp. 1-28). London: Routledge.

Feldman, Y., \& Lobel, O. (2008). Decentralized enforcement in organizations: An experimental approach. Regulation \& Governance, 2(2), 165-192.

Hersh, M. A. (2002). Whistleblowers-heroes or traitors?: Individual and collective responsibility for ethical behaviour. Annual Reviews in Control, 26(2), 243-262. 
Johnson, R. A. (2004). Corruption in four countries. In The Struggle Against Corruption: A Comparative Study (pp. 145-165). Palgrave Macmillan, New York.

King III, G. (1999). The implications of an organization\&\#39;s structure on whistleblowing. Journal of Business Ethics, 20(4), 315-326.

Lewis, D. (2006). The contents of whistleblowing/ confidential reporting procedures in the UK: Some lessons from empirical research. Employee Relations, 28(1), 76-86.

Near, J. P., \&Miceli, M. P. (1996). Whistle-blowing: Myth and reality. Journal of management, 22(3), 507526.

Schmidt, M. (2005). "Whistle blowing" regulation and accounting standards enforcement in Germany and
Europe - an economic perspective. International Review of Law and Economics, 25(2), 143-168.

Schoemaker, P. J. (1995). Scenario planning: a tool for strategic thinking. Sloan management review, 36(2), 25.

Teo, H., \& Caspersz, D. (2011). Dissenting discourse: Exploring alternatives to the whistleblowing/silence dichotomy. Journal of Business Ethics, 104(2), 237-249.

Uys, T. (2008). Rational loyalty and whistleblowing: The South African context. Current Sociology, 56(6), 904-921.

Vandekerckhove, W. (2006). Whistleblowing and Organizational Social Responsibility: A Global Assessment (Corporate Social Responsibility). 